\title{
Informe de la Mesa Directiva de la Sociedad Colombiana de Obstetricia y Ginecología en el periodo 1953 - 1954
}

Los miembros de la Mesa Directiva de la Saciedad, en el perído que hoy termina, se preocipuron seriamente por los problemas de la corporación y se cmpeñaron en desurollar un amplio programa cientifico y gremial.

En el campo cientifico, se consiguieron estas realizaciones: La Sociedad lelró sus sesiones ordinarias con regularidad y cumplimiento una vez por mes; una ocasión no habo sesion por falta de lecal). Durrante las sesiones se dio peferencia a los temas cientificos; en esta forma, la Sociedad adquirió más semidad y mayor efectividad.

La Mesa Directiva dio nucvo impulso y vitalidad a la Revista, que hoy día as un órgano netamente cientifico. No tiene color politico ninguno, ni defiende "ni ataca intereses de ningín grupo. $S_{u}$ finalidad no es económica sino de difuvin cicntifica y de intercambio cultural con todos los colegas del país y por lo numo también es secundariamente un factor de acercamiento gremial. Su distrithe win es profusa dentro y fuera del pais.

Creamos el Comité Nacional de Redaccioin de la Revista, con lo cual lograun vínculo muy poderoso con todos los obstetras y ginecólogos de la nación.

Se presentaron los siguientes trabajos cientificos:

"Procaina intravenosa en los espasmos cervicales", por el Dr. Jorge Ortiz (iamboa.

Informe de Comision: "Procaina intravenosa y parto en primípara avanzanda", por el Dr. Carlos Roberto Silva Mojica.

"Nucva orientación terapéutica en la eclampsia", por el Dr. Luis Guiller(ubillos.

Informe de Comision: "Juicio critico sobre el trabajo de "forceps alto", del Dr. Isaías Arenas Buenahora, por el Prof. Rafuel Ramírez Merchán.

Trabajos del Dr. Jose Ofman: "Un caso de fibromioma y embarazo" y "Ob. servaciones de bloqueo pudendo en el parto". 
Informe de Comisión sobre los trabajos del Dr. Ofman, por el Dr. Luis Givillermo Cubillos.

"Comentarios sobre los tratamientos de las toxemias gravídicas", por el Dr. Carlos R. Silva Mojica.

"Noventa y cinco casos de embarazo ectópico", por el Dr. Jesús A. Gómez Palacino.

Informe de Comision: "Inicio critico sobre el trabajo del Dr. Coimez Pala. cino", por el Dr. Carlos R. Silva Mojica.

Creamos además la Comisión de estudio de la toxemia graridica, que viene juncionando activamente desde principios de este año.

Llevamos a efecto la Primera Convención Nacional do Obstetricia y Gine. cologia, que constituyó un gran éxito cientifico, gremial y social y a la cual asis. tieron 250 colegas de todo el pais. A este certamen se presentaron en total 52 trabajos científicos: 27 de Obstetricia y 25 de Ginecología. Se llegó a conclusio. nes importantes en cuanto a toxemias, factor $R h$, esterilidad y algunos temas $h$ bies y se fijaron los temas y la sede de la próxima Convención. Es de anotar que en este certamen dejamos de lado pequeñas rencillas personales y diferencias de grupo en pro del adelanto cientifico y buen resultado de la Convención.

Organizamos un concurso cientifico con el fin de enviar un observador al Segundo Congreso Latino Americano de Obstetricia y Ginecología que se reu. nirá en San Pablo, Brasil, el 9 de julio de 1954.

Dotamos a la Sociedad y a la Revista de local y oficina propios, equipados con todos los clementos necesarios que demanda nuestra corporacion: secretaria, míquina de escribir, escritorio, archivo, muebles, etc., etc.

En el campo gremial nuestra labor fue menos efectiva, debido a diversos factores: incomprension de los colegas, desatencion de las directivas del ICSS e inefectividad de autoridades competentes. Sin embargo manifestamos que nos desvelamos honradamente por buscar solución a los graves problemas que ha te. nido que afrontar la Sociedad.

Como todos lo saben, el proyecto de nueva organización de los servicios obs: tétricos en la Clinica Primero de Mayo, elaborado por la Mesa Directiva, en aso: cio de los doctores Victor Rodriguez Aponte y Camilo Casas, y de acuerdo cos el Médico Jefe del ICSS, fue a dar a la canasta de los papelés inutiles del Ge rente y del Dr. Jiménez Cadena.

Pero es justo anotar que el ICSS en parte aceptó nuestras peticiones: per mitió el ingreso a la nómina de obstetras de la Clínica Primero de Mayo a ewo tro apreciados colegas, los doctores Ortiz Ciamboa, Rodriguez Astié, Salazar De vila, Sanz Araoz, y asi mismo aceptó el ascenso al grupo de consultores, de bs doctores Riaño, Salamanca, Hunda y Giraldo. 
Personalmente expusimos al señor Ministro de Higiene la situación anómala de 50 obstetras que trabajan supervigilados por un inquisidor de especialidad ambigua. El señor Ministro permanecio sordo y estas condiciones inaceptables han persistido. En las conclusiones de la Convencion de Olestetricia , Cinecologia puntualizamos enfáticamente la necesidad de que las clinicas ob tetricas estén dirigidas por especialistas en esta materia.

El problema de la Clinica "David Restrepo" continia en pie y no por faltu he voluntad e interes nuestro para resolverlo. Este asunto quedo encomendade. l Prof. Luis María Ferro, pero ignoramos el resultado de sus gestiones.

Concientes de nuestra responsabilidad en relación con los proyectos que we el ICSS, hicimos ratificar el pacto de honor firmado en 1949 y en 1951. La actitud de nuestra Sociedad en este sentido es decisiva para el porvenir de los médicos de Colombia; tanto la Federación Médica Colombiana como las demas Sociedades cientificas, esperan nuestra reacción y nuestra conducta para proceder en consecuencia. Aclaramos que quien firma un pacto empeña su palabru, s" prestigio, su honorabilidad. El violar un convenio no es sino una afrenta ? "1. irrespeto a la propia personalidad. Quien calladamente acepte propuestas "yte atenten contra la estabilidad de la Sociedad no hace más que exponer la C... era científica de sus compañeros y el prestigo de la corporacion a la derrota 1.1 fracaso.

Confiados en el alto sentido de rectitud y compañerismo que anima a todos los miembros de la Sociedad, esperamos que ella salga triunfante de la recia lucha que actualmente se inicia.

Entregamos la dirección de la Sociedad, satisfechos del esfuerzo realizado pura su mejoramiento y progreso y auguramos a la nueva Directina grandes criter en el campo científico y en el campo gremial.

Pum. Anturo Aparicio Jaramillo
Presidente.

lilo.). (Fdo.),

1). Finnando Tamayo Secretario

Prof. Santiago lilmas Comazzi Tesorero. 